\title{
Causality Analysis for Public and Private Expenditures on Health Using Panel Granger-Causality Test
}

\author{
Su-Dong Lee, Junghye Lee, Chi-Hyuck Jun* \\ Department of Industrial \& Management Engineering, Pohang University of Science and Technology, \\ Pohang, Korea
}

(Received: March 2, 2015 / Revised: March 16, 2015 / Accepted: March 17, 2015)

\begin{abstract}
Every year governments spend their national budget on public health in order to reduce financial burden of individuals on health. Although it has been widely believed that the increase of public expenditure on health decreases private health expenditure, it has not been proved by analysis with real data. For better understanding, we conducted an empirical study on the real data of 17 OECD countries-Australia, Austria, Canada, Denmark, Finland, Germany, Iceland, Ireland, Japan, Korea, New Zealand, Norway, Portugal, Spain, Sweden, the United Kingdom, and the United States. The panel Granger-causality test is used to verify the cause-and-effect relationship between the two expenditures. As a result, public expenditure on health has a 3 to 4 year-lagged negative effect on private health expenditure in the cases of the 16 countries except for the United States.
\end{abstract}

Keywords: Panel Granger-Causality Test, Public Health, Health Expenditure

* Corresponding Author, E-mail: chjun@postech.ac.kr

\section{INTRODUCTION}

When policy makers build a healthcare budget policy, they have to consider their fiscal constraint and balance between public and private expenditure. For that reason, it is important to better understand the relationship between them. Even though it is widely believed that the increase of public expenditure on health decreases private one, it has never been proved by analysis with real data yet and still remains controversial.

Tuohy et al. (2004) carried out a study to verify the impact of private finance on public healthcare system. However, the hypothesis is supposed in the opposite direction to ours, "Governments distribute public expenditure on health expecting that it should help nationals keep health and ease the burden of health expenditures." In fact, there are several empirical studies about the rela- tionship between healthcare expenditure and health status of individuals although no a consensus has been made; some studies have shown significant impact of healthcare spending on health of the nation (Akinkugbe and Afeikhena, 2006; Anyanwu and Erhijakporm, 2007) while others did not find any significant relationship between them (Musgrove, 1996; Burnside and Dollar, 1998). When it comes to the effect of public health expenditure on the private health expenditure, no outstan-ding studies have been found yet.

Therefore, in the present study, we focus on figuring out if public expenditures on health help to decrease private ones or not across nations by panel data analysis using the empirical data of 17 OECD countries. To be more specific, we apply panel Granger-causality tests under the assumption that there should be time lags causing preceding effects. In the area of healthcare, several 
researchers have been interested in macroeconomic growth studies with a focus on health (Hartwig, 2010) using Granger-causality tests.

The paper is organized as follow. The next section introduces the data and methodologies we used. Section 3 shows the results of empirical analysis, and Section 4 concludes.

\section{DATA AND METHODOLOGY}

\subsection{Data}

To verify the causal relationship between public and private expenditures on health, yearly per-capita heal-thcare expenditure by general governments and individuals of the 17 countries-Australia, Austria, Canada, Denmark, Finland, Germany, Iceland, Ireland, Japan, Korea, New Zealand, Norway, Portugal, Spain, Sweden, the United Kingdom, and the United States-from 1980 to 2010 were collected from the OECD's Health database (in the version of June 2013). Before the causality test, a 'de-inflation' process is necessary to eliminate the effect by inflation which is irrelevant to the causality of our interest. To do so, we collected the inflation rate of the corresponding period from the same data source and removed the upward trend of expenditure due to general inflation. Then we named the public and private expenditure on health of each country as $P U B$ and PRIV respectively.

\subsection{Methodology}

\subsubsection{Panel unit root test}

Since the panel Granger-causality test requires the data to be stationary, the time series should be tested for the existence of unit roots. Levin-Lin-Chu test (Levin, Lin and $\mathrm{Chu}, 2002$ ) is one of the most well-known unit root testing methods for panel data in which the hypotheses are

$$
\begin{aligned}
& H_{0} \text { : each time series contains a unit root } \\
& H_{1} \text { :each time series is stationary }
\end{aligned}
$$

where the lag order is permitted to vary across individuals. If the null hypothesis is accepted, $k$-order differencing with a proper $k$ can be taken in order to make the time series stationary. In the present study, we take the $1^{\text {st }}$-order differencing $\left(\nabla X_{t}=X_{t}-X_{t-1}\right)$ each time when $H_{0}$ is accepted and repeat the test until it is rejected.

\subsubsection{Panel granger-causality test}

According to Granger (1969), a stationary time series $Y_{t}$ is said to 'cause' another stationary time series $X_{t}$ if-under the assumption that all other information is irrelevant-the inclusion of past values of $Y_{t}$ significantly reduces the predictive error variance of $X_{t}$. Whe- ther $Y_{t}$ Granger-causes $X_{t}$ is typically tested by regressing $X_{t}$ on its own lags and on lags of $Y_{t}$. If the lags of $Y_{t}$ are found to be jointly statistically significant, then the hypothesis that $Y_{t}$ Granger-causes $X_{t}$ cannot be rejected. Based upon that, we will estimate a time-stationary VAR (vector auto-regressive) model adapted to a panel context as in Holtz-Eakin et al. (1988) of the form:

$$
X_{i t}=\alpha_{0}+\sum_{i=1}^{m} \alpha_{i} X_{i, t-i}+\sum_{i=1}^{m} \delta_{l} Y_{i, t-i}+\mu_{i}+u_{i t}
$$

$X_{i t}$ and $Y_{i t}$ respectively indicate $P R I V$ and $P U B$ of country $i(\mathrm{i}=1, \cdots, N)$ observed at $t(t=1, \cdots, T)$ having $\alpha_{i}$ and $\delta_{i}$ as their coefficients of lag $l(l=1, \cdots, m) . \mu_{i}$ stands for a country-specific mean explaining idiosyncratic characteristics of each country and a disturbance $u_{i t}$ is assumed to be independently distributed across countries with a zero mean. The rest of information unexplained is expressed using the constant term $\alpha_{0}$.

\section{RESULTS}

\subsection{Panel Unit Root Test}

Before applying the panel Granger causality test, we conducted the panel unit root testing first. For all the following experiments, EViews (version 7) was used. Table 1 shows the result of Levin-Lin-Chu test on the $P U B$ and PRIV of 17 OECD countries from 1980 to 2010.

As Table 1 shows, the null hypotheses are accepted for both $P U B$ and PRIV so it can be said that the two time series are non-stationary. We take $1^{\text {st }}$-order differencing for both, afterwards; the null hypotheses are rejected as shown in Table 2 . So, we use the $1^{\text {st }}$-order differenced value for both $P U B$ and $P R I V$ for the following analysis procedures.

Table 1. Panel unit root test results (17 OECD countries, 1980-2010)

\begin{tabular}{ccc}
\hline \multirow{2}{*}{$\mathrm{H}_{0}$ : Unit root in level } & \multicolumn{2}{c}{ Levin-Lin-Chu test } \\
\cline { 2 - 3 } & Stat. & $p$-value \\
\hline PUBLIC $(P U B)$ & 6.4972 & 1.0000 \\
PRIVATE $(P R I V)$ & 3.5081 & 0.9998 \\
\hline
\end{tabular}

Table 2. Panel unit root test results (17 OECD countries, 1980-2010) after $1^{\text {st }}$-order differencing

\begin{tabular}{ccc}
\hline \multirow{2}{*}{$\mathrm{H}_{0}$ : Unit root in level } & \multicolumn{2}{c}{ Levin-Lin-Chu test } \\
\cline { 2 - 3 } & Stat. & $p$-value \\
\hline PUBLIC $($ PUB $)$ & -8.9743 & 0.0000 \\
PRIVATE $(P R I V)$ & -8.0846 & 0.0000 \\
\hline
\end{tabular}




\subsection{Model Selection}

The result of a panel Granger-causality test largely depends on the lag length $m$ in the time-stationary VAR model given by Eq. (2). Therefore, it is important to appropriately specify the lag structure. We estimate the parameters in Eq. (2) using ordinary least squares based on the Schwarz Information Criterion (SIC) to choose the optimal lag length. Figure 1 shows SIC scores corresponding to different lag lengths. In general, an optimal lag length may be set shorter than 5 to build a stable model so that it seems reasonable to choose lag 1 of the smallest SIC in that region, however, we also consider lag 11 since $P U B$ may have a long term effect on $P R I V$. Actually, the model with lag 11 has the lowest SIC score.

\subsection{Panel Granger-Causality Test}

First, we have a model with lag 1 as follows:

$$
X_{i t}=\alpha_{0}+\alpha X_{i, t-1}+\delta Y_{i, t-i}+\mu_{i}+u_{i t}
$$

We estimated the parameters of Eq. (3) and the results are shown in Table 3. As we can see, no explanatory variables have significant effects on PRIV.
Table 3. Estimation results for Eq. (3)

\begin{tabular}{lccc}
\hline & C & PUBLIC(-1) & PRIVATE(-1) \\
\hline Coefficient & $6.772630^{* * *}$ & 0.020286 & 0.002645 \\
Std. Error. & $(0.904248)$ & $(0.026319)$ & $(0.049554)$ \\
\hline
\end{tabular}

${ }^{*},{ }^{* *},{ }^{* * *}$ : Significant at $\alpha=0.10,0.05,0.01$ respectively.

With lag 11, we have a model as follows:

$$
X_{i t}=\alpha_{0}+\sum_{i=1}^{11} \alpha_{i} X_{i, t-i}+\sum_{i=1}^{11} \delta_{i} Y_{i, t-i}+\mu_{i}+u_{i t}
$$

The parameter estimation results of Eq. (4) are shown in Table 4. PUB of lag 11 has a significant effect on PRIV at $\alpha=0.10$.

\subsection{Robustness Test}

Since a panel data analysis is highly sensitive to outliers, tests are necessary to verify robustness of the models and to find out outliers. For all the 17 countries, leave-one-out re-estimations of Eq. (4) for lag 11, which has the minimum SIC score, were conducted by dropping each country in turn. As a result, it turns out that

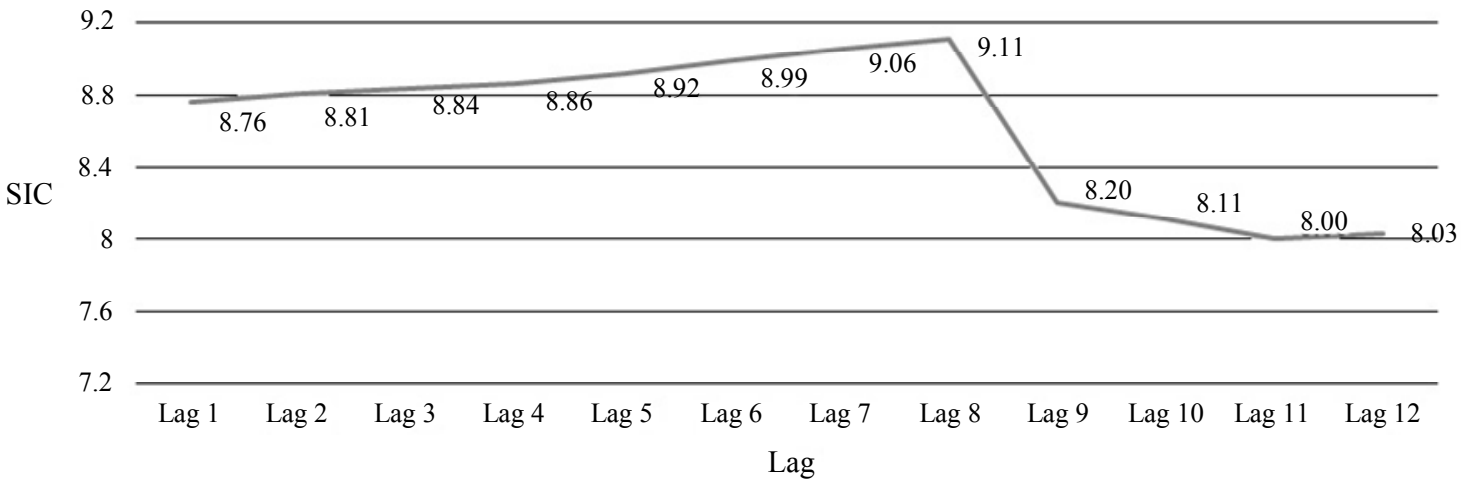

Figure 1. SIC scores according to different lag lengths.

Table 4. Estimation results of Eq. (4)

\begin{tabular}{cccccc}
\hline C & PRIV (-1) & PRIV $(-2)$ & PRIV (-3) & PRIV (-4) & PRIV (-5) \\
\hline $9.8867^{* * *}$ & 0.1510 & 0.0211 & -0.0787 & 0.0074 & -0.1931 \\
$(1.4676)$ & $(0.0549)$ & $(0.0548)$ & $(0.0375)$ & $(0.0364)$ & $(0.0365)$ \\
\hline PRIV (-6) & PRIV (-7) & PRIV $(-8)$ & PRIV $(-9)$ & PRIV $(-10)$ & PRIV (-11) \\
\hline-0.0846 & -0.0389 & -0.1041 & 0.0333 & -0.0709 & -0.1108 \\
$(0.0374)$ & $(0.0376)$ & $(0.0366)$ & $(0.0363)$ & $(0.0356)$ & $(0.0343)$ \\
\hline PUB (-1) & PUB (-2) & PUB (-3) & PUB (-4) & PUB (-5) & PUB (-6) \\
\hline 0.01970 & 0.0214 & -0.0227 & -0.0152 & 0.0195 & -0.0135 \\
$(0.0271)$ & $(0.0260)$ & $(0.0215)$ & $(0.0199)$ & $(0.0201)$ & $(0.0202)$ \\
\hline PUB (-7) & PUB (-8) & PUB (-9) & PUB (-10) & PUB $(-11)$ & \\
\hline-0.0158 & 0.0120 & -0.0008 & 0.0274 & $0.0361^{*}$ & \\
$(0.0203)$ & $(0.0195)$ & $(0.0192)$ & $(0.0187)$ & $(0.0188)$ & \\
\hline
\end{tabular}

${ }^{*},{ }^{* *},{ }^{* * *}$ : Significant at $\alpha=0.10,0.05,0.01$ respectively. 
the model is indeed sensitive to some extent to the exclusion of several countries such as Ireland, Norway, Japan and the United States while the results of the other cases are similar to each other. When excluding each of the first three countries, relatively small difference turns out that $D P U B(-11)$ has no significant effect. In contrast, the re-estimation result without the United States is far different from the other case as seen in Table 5. For comparison, the case without Austria which is one of the countries yielding no big differences from the others is

Table 5. Robustness test for cross-national stability of parameters of Eq. (4)

(a) Re-estimation results excluding the United States

\begin{tabular}{|c|c|c|c|c|c|}
\hline \multicolumn{3}{|c|}{ The United States excluded } & \multicolumn{3}{|c|}{ Austria excluded } \\
\hline Variable & Coefficient & Std. Error & Variable & Coefficient & Std. Error \\
\hline $\mathrm{C}$ & $6.138571^{* * *}$ & 1.208443 & $\mathrm{C}$ & $9.998630^{* * *}$ & 1.437171 \\
\hline DPUB(-1) & 0.013706 & 0.024021 & DPUB(-1) & 0.014569 & 0.028184 \\
\hline DPUB(-2) & 0.012208 & 0.023072 & DPUB(-2) & 0.037680 & 0.028163 \\
\hline DPUB(-3) & $-0.032005^{*}$ & 0.019242 & $\operatorname{DPUB}(-3)$ & -0.029309 & 0.022255 \\
\hline $\operatorname{DPUB}(-4)$ & $-0.030330^{*}$ & 0.018190 & $\operatorname{DPUB}(-4)$ & -0.018701 & 0.020734 \\
\hline DPUB(-5) & 0.012116 & 0.018502 & DPUB(-5) & 0.019406 & 0.020961 \\
\hline DPUB(-6) & -0.018470 & 0.018550 & DPUB(-6) & -0.016808 & 0.021102 \\
\hline DPUB(-7) & -0.017248 & 0.018734 & DPUB(-7) & -0.014309 & 0.021233 \\
\hline DPUB(-8) & -0.003027 & 0.017756 & DPUB(-8) & 0.016723 & 0.020199 \\
\hline DPUB(-9) & -0.011276 & 0.017528 & DPUB(-9) & -0.004697 & 0.019922 \\
\hline DPUB(-10) & 0.025566 & 0.016955 & DPUB(-10) & 0.019987 & 0.019272 \\
\hline DPUB(-11) & 0.022656 & 0.016933 & DPUB(-11) & $0.041653^{* *}$ & 0.019319 \\
\hline DPRI(-1) & 0.041968 & 0.057867 & DPRI(-1) & $0.153753^{* * *}$ & 0.055951 \\
\hline DPRI(-2) & 0.035827 & 0.055773 & DPRI(-2) & 0.050282 & 0.057392 \\
\hline DPRI(-3) & 0.043873 & 0.053050 & DPRI(-3) & $-0.088445^{* *}$ & 0.037960 \\
\hline DPRI(-4) & $0.097666^{*}$ & 0.052347 & DPRI(-4) & 0.003465 & 0.036841 \\
\hline DPRI(-5) & -0.051743 & 0.053878 & DPRI(-5) & $-0.201034^{* * *}$ & 0.037053 \\
\hline DPRI(-6) & -0.003308 & 0.053669 & DPRI(-6) & $-0.095797^{* *}$ & 0.038291 \\
\hline DPRI(-7) & -0.021805 & 0.054324 & DPRI(-7) & -0.034451 & 0.038205 \\
\hline DPRI(-8) & -0.003231 & 0.052096 & DPRI(-8) & $-0.116159^{* * *}$ & 0.037242 \\
\hline DPRI(-9) & 0.058958 & 0.050571 & DPRI(-9) & 0.023850 & 0.036982 \\
\hline DPRI(-10) & -0.060053 & 0.050301 & DPRI(-10) & $-0.067162^{*}$ & 0.036234 \\
\hline DPRI(-11) & 0.004706 & 0.046290 & DPRI(-11) & $-0.140528^{* * *}$ & 0.035663 \\
\hline
\end{tabular}

${ }^{*},{ }^{* *},{ }^{* * *}$ : Significant at $\alpha=0.10,0.05,0.01$ respectively.

USD (million)

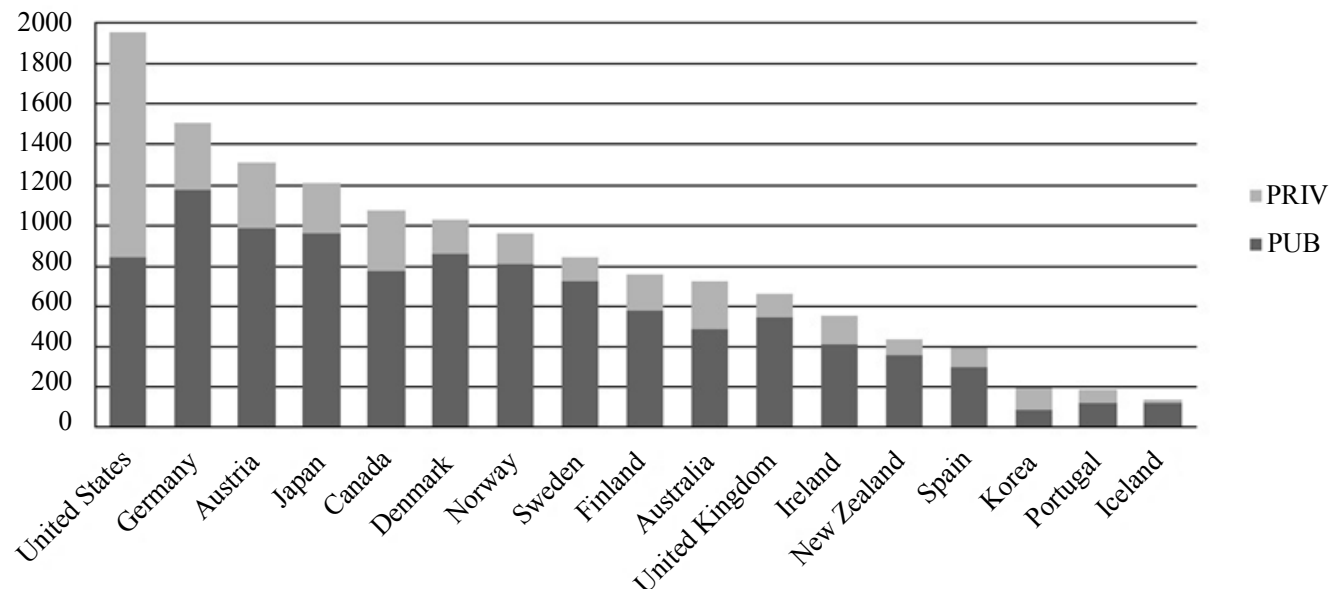

Figure 2. $P U B$ and $P R I V$ of the 17 OECD countries (1980-2010). 
shown together while the rest of results for 15 countries is in Appendix.

To be more specific, we compare the amount of PUB and PRIV of the 17 countries over 1980-2010. As Figure 2 shows, the United States has a distinctive pattern in terms of not only the absolute scale of health expenditure but also the ratio between $P U B$ and PRIV. Those may make the United States be an outlier from the other countries though further qualitative analysis is required for better understanding.

So, we remove the United States and go through the previous procedures-unit root testing, model selection and parameter estimation - again. As same as before, we saw the existence of unit roots then took $1^{\text {st }}$-order differencing. With the differenced data, we found that the optimal lag length is 11 again. As a result, we obtained the final estimation results for the coefficients as in Table 6.

According to Table 6 , in the 16 OECD countries except for the United States, $P U B$ has a significant negative effect on PRIV after 3-4 years and PRIV is autocorrelated itself with 4-year lag.

\section{DISCUSSION}

In this paper, we provide a comprehensive procedure of an empirical study with a panel time series data set to verify the effect of public health expenditure on the private one. By applying the panel Granger-causality test on the collected real data sets of 17 OECD countries, it turned out that public expenditure on health has a 3-4 year-lagged negative effect on private health expenditure in the cases of the 16 countries-Australia, Austria, Canada, Denmark, Finland, Germany, Iceland, Ireland, Japan, Korea, New Zealand, Norway, Portugal, Spain, Sweden and the United Kingdom-except for the United States. The United States shows their own particular pattern which is distinctive from the other OECD countries. Further qualitative analysis on that may be helpful for better understanding.

Besides the issue, what does the finding for the 16 countries mean? Corresponding to the hypothesis we have tested, it turned out that the public expenditure on health negatively Granger-causes private health expenditure. However, the effect is valid after a certain time period rather than in immediate response to the public expenditure. Based upon the results of our empirical analysis, we estimate the length of time needed for public expenditure to have an actual effect on the decrease of private expenditure as about 3-4 years.

For future works, we have several considerations. In terms of methodologies, more flexible and complex models can be used for more elaborate analysis. For instance, we can relax the constraint that the optimal lags of PRIV and PUB in explanatory variables have to be set the same. If a model that has different lags for each of them is available, it may better explain the data. Further, we may also build a variety of sophisticated models. When it comes to selecting variables, different scenarios can be assumed. For the follow-up studies, we have some ideas of adding macroeconomic factors and national indices related to health such as smoking rate and obesity rate. Using more variables implying different kinds of information, it is expected to explain diverse relationships between attributes related to national health.

\section{ACKNOWLEDGEMENT}

This research was supported by National Research Foundation of Korea (Project No. 2013R1A2A2A0306 8323).

\section{REFERENCES}

Akinkugbe, O. and Afeikhena, J. (2006), Public health

Table 6. Estimation results without the United States

\begin{tabular}{|c|c|c|c|c|c|}
\hline $\mathrm{C}$ & PUB (-1) & PUB (-2) & PUB (-3) & PUB (-4) & PUB (-5) \\
\hline $\begin{array}{l}6.138571^{* * * *} \\
(1.208443)\end{array}$ & $\begin{array}{c}0.013706 \\
(0.024021) \\
\end{array}$ & $\begin{array}{c}0.012208 \\
(0.023072) \\
\end{array}$ & $\begin{array}{l}-0.032005^{*} \\
(0.019242) \\
\end{array}$ & $\begin{array}{l}-0.030330^{*} \\
(0.018190)\end{array}$ & $\begin{array}{c}0.012116 \\
(0.018502) \\
\end{array}$ \\
\hline PUB (-6) & PUB (-7) & PUB (-8) & PUB (-9) & PUB (-10) & PUB (-11) \\
\hline $\begin{array}{c}-0.018470 \\
(0.018550) \\
\end{array}$ & $\begin{array}{c}-0.017248 \\
(0.018734) \\
\end{array}$ & $\begin{array}{c}-0.003027 \\
(0.017756) \\
\end{array}$ & $\begin{array}{c}-0.011276 \\
(0.017528) \\
\end{array}$ & $\begin{array}{c}0.025566 \\
(0.016955) \\
\end{array}$ & $\begin{array}{c}0.022656 \\
(0.016933) \\
\end{array}$ \\
\hline PRIV (-1) & PRIV (-2) & PRIV (-3) & PRIV (-4) & PRIV (-5) & PRIV (-6) \\
\hline $\begin{array}{c}0.041968 \\
(0.057867)\end{array}$ & $\begin{array}{c}0.035827 \\
(0.055773)\end{array}$ & $\begin{array}{c}0.043873 \\
(0.053050)\end{array}$ & $\begin{array}{c}0.097666^{*} \\
(0.052347)\end{array}$ & $\begin{array}{c}-0.051743 \\
(0.053878)\end{array}$ & $\begin{array}{c}-0.003308 \\
(0.053669)\end{array}$ \\
\hline PRIV (-7) & PRIV (-8) & PRIV (-9) & PRIV (-10) & PRIV (-11) & \\
\hline $\begin{array}{c}-0.021805 \\
(0.054324) \\
\end{array}$ & $\begin{array}{c}-0.003231 \\
(0.052096) \\
\end{array}$ & $\begin{array}{c}0.058958 \\
(0.050571) \\
\end{array}$ & $\begin{array}{c}-0.060053 \\
(0.050301) \\
\end{array}$ & $\begin{array}{c}0.004706 \\
(0.046290) \\
\end{array}$ & \\
\hline
\end{tabular}

${ }^{*},{ }^{* *},{ }^{* * *}$ : Significant at $\alpha=0.10,0.05,0.01$ respectively. 
care spending as a determinant of health status: a panel data analysis for SSA and MENA, Applied macroeconomics and economic development, Ibadan University Press.

Anyanwu, C. J. and Erhijakpor, E. O. A. (2007), Health expenditures and health outcomes in Africa, African Development Bank Economic Research, Working Paper No 91.

Burnside, C. and Dollar, D. (1998), Aid, the incentive regime and poverty reduction, The World Bank, Washington DC.

Granger, C. W. J. (1969), Investigating causal relations by econometric models and cross-spectral methods, Econometrica, 37, 424-438.

Hartwig, J. (2010), Is health capital formation good for long-term economic growth?-Panel Granger-causality evidence for OECD countries, Journal of macroeconomics, 32(1), 314-325.
Holtz-Eakin, D., Newey, W., and Rosen, H. (1988), Estimating vector autoregressions with panel data, Econometrica, 56, 1371-1395.

Levin, A., Lin, C. F., and Chu, C. S. J. (2002), Unit root tests in panel data: Asymptotic and finite-sample properties, Journal of Econometrics, 108, 1-24.

Motonishi, T. and Yoshikawa, H. (1999), Causes of the long stagnation of Japan during the1990s: financial or real, Journal of the Japanese and International Economies, 13, 181-200.

Musgrove, P. (1996), Public and private roles in health, Technical report 339, The World Bank, Washington DC.

Tuohy, C. H., Flood, C. M., and Stabile, M. (2004), How does private finance affect public health care systems? Marshaling the evidence from OECD nations, Journal of Health Politics, Policy and Law, 29(3), 359-396. 


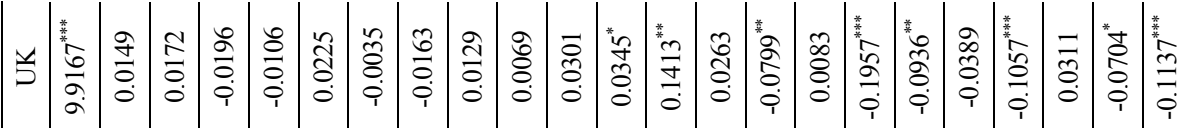

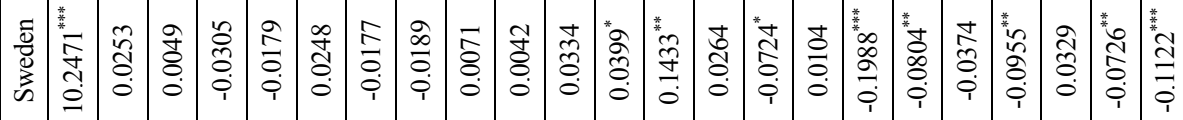

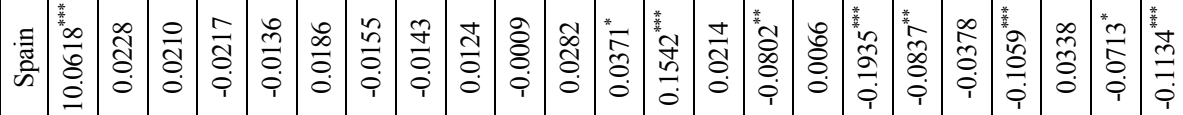

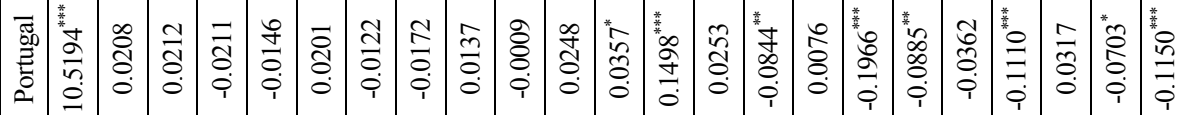

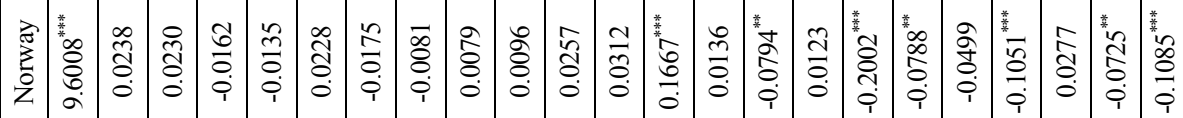

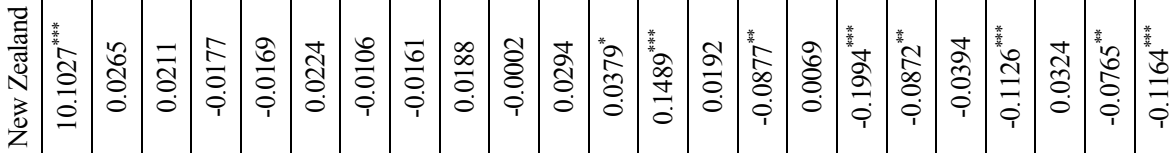

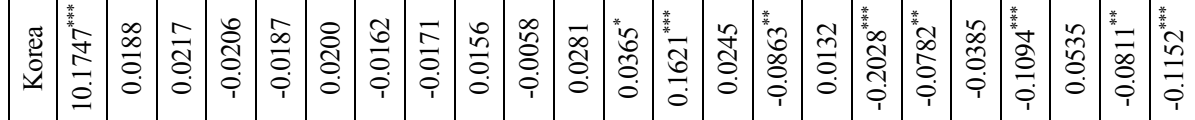

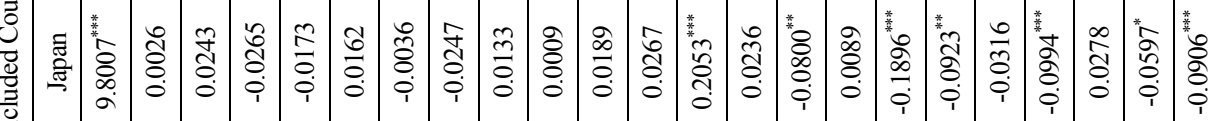

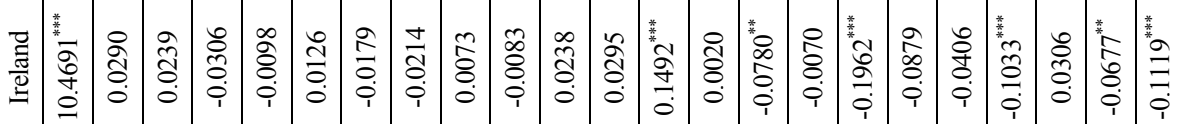

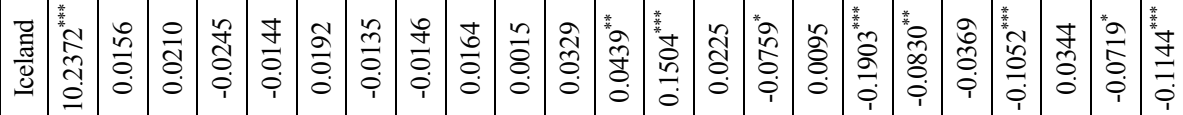

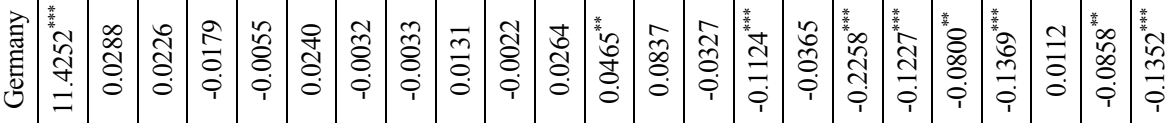

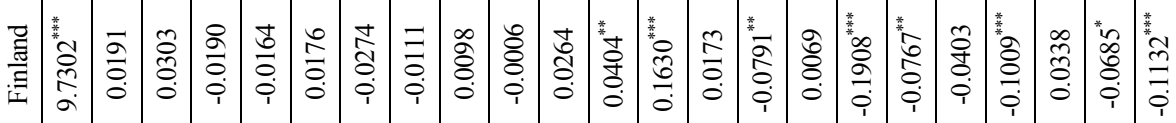

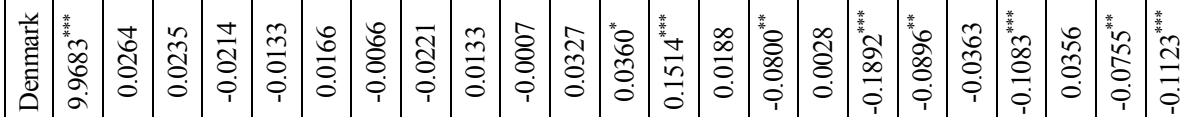

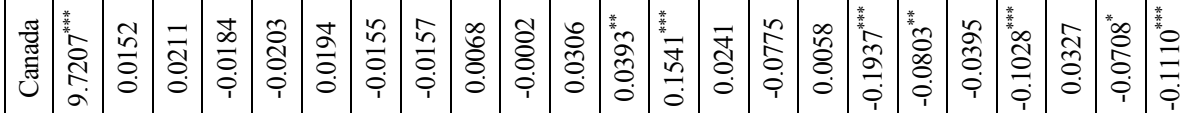

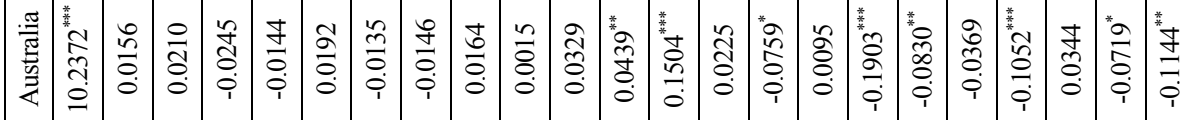

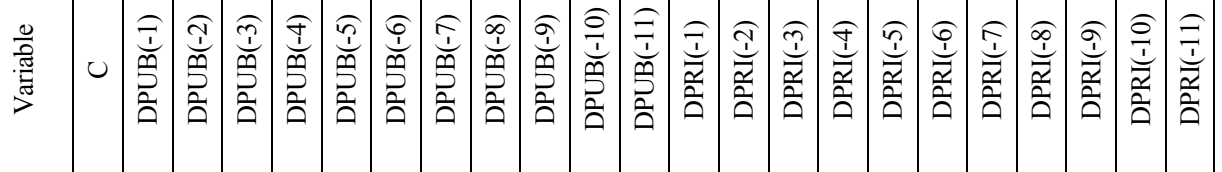

